\title{
Uma tarefa crucial para a economia política: a crítica da inovação tecno-liberal
}

A Crucial Task for the Political Economy: A Critique of Techno-liberal Innovation Une tâche cruciale pour l'économie politique: la critique de l'innovation technolibérale

José Luís Garcia

\section{OpenEdition} Journals

Edição electrónica

URL: http://journals.openedition.org/rccs/9316

DOl: $10.4000 /$ rccs.9316

ISSN: 2182-7435

Editora

Centro de Estudos Sociais da Universidade de Coimbra

Edição impressa

Data de publição: 1 Setembro 2019

Paginação: 171-198

ISSN: 0254-1106

\section{Refêrencia eletrónica}

José Luís Garcia, «Uma tarefa crucial para a economia política: a crítica da inovação tecno-liberal », Revista Crítica de Ciências Sociais [Online], 119 | 2019, colocado online no dia 06 agosto 2019, criado a 08 agosto 2019. URL : http://journals.openedition.org/rccs/9316 ; DOI : 10.4000/rccs.9316 


\section{JOSÉ LUÍS GARCIA}

\section{Uma tarefa crucial para a economia política: a crítica da inovação tecno-liberal*}

Este artigo procede a uma crítica à inovação impulsionada, desde as décadas finais do século $\mathrm{xx}$, como grande projecto das sociedades. O texto apresenta duas contribuições principais para a elucidação do que está em causa nesse empreendimento. A primeira consiste em sustentar que a orientação para a inovação é uma política económica, de carácter neoliberal, que tem como objectivo o aumento da produtividade e dos lucros, através da anexação da ciência e da tecnologia, e abrindo o caminho aos mercados de novos âmbitos do mundo natural e da vida humana. A segunda é sugerir que o projecto da inovação é uma nova manifestação de historicismo, mais propriamente de historicismo tecno-liberal. O texto conclui com a defesa da necessidade de avaliar as políticas da inovação segundo valores adequados para alcançar fins socialmente equitativos e ecologicamente viáveis.

Palavras-chave: economia do conhecimento; historicismo; inovação tecnológica; neoliberalismo; política de inovação.

\section{Introdução}

O objectivo deste artigo é apresentar uma reflexão crítica da política de inovação implementada, desde finais da década de 1980, como grande desígnio das sociedades. Esta crítica pretende demonstrar que a política de inovação tem sido uma construção política, de cunho neoliberal, institucionalizada e desenvolvida por Estados, agências nacionais, entidades supranacionais e grandes empresas, ao serviço da expansão do controlo privado da economia, do mercado em mais domínios da vida humana e natural e da produção para o lucro. A discussão realizada elucida como o compromisso da actual política de inovação é sobretudo com a criação constante de invenções,

\footnotetext{
* Este artigo é uma versão alterada de uma comunicação do autor apresentada, como um dos keynote speakers, no I Encontro de Economia Política, que se realizou entre 25 e 27 Janeiro de 2018, no ISCTE-IUL, em Lisboa.

Por vontade do autor, o texto não segue as regras do Acordo Ortográfico de 1990.
} 
em especial tecnológicas ou com componente tecnológica, passíveis de serem convertidas em mercadorias altamente rentáveis na presente economia mundial, e que para esse fim, tem sido fulcral a cooptação e transformação da investigação científica e tecnológica e de outras formas de conhecimento e informação.

Este ensaio afasta-se das pressuposições teóricas que justificam o viés pró-inovação hegemónico no campo de pesquisa da inovação em ciências sociais e insere-se na corrente de estudos críticos e na procura de alternativas (Godin, 2016, 2017; Garcia et al., 2018; Grunwald, 2018; Kerschner et al., 2018; Pollex e Lenschow, 2018; Strand et al. 2018). As principais questões-chave a que o artigo busca dar resposta são: como compreender que a política de inovação seja acolhida socialmente como se fosse um inelutável destino? Qual o sentido de a política de inovação ter como entendimento fundamental a mudança tecnológica e a economia? Quais as implicações geradas pela vaga de inovações das últimas décadas?

O presente texto sugere uma abordagem original neste campo de estudos através da introdução de duas perspectivas. A primeira defende que o projecto de inovação constitui uma nova manifestação de historicismo, em concreto o historicismo simultaneamente tecnológico e mercadológico, numa expressão, o historicismo tecno-liberal. O artigo sustenta que, a partir de uma falaciosa representação da história como o cumprimento de um processo evolutivo e ascendente da liberdade e da racionalização das relações entre os seres humanos e destes com a natureza, as tecnologias/ /mercadorias produzidas pela inovação aparecem como sendo sempre superiores às do passado e o sistema de mercado como um sistema terminal. A segunda perspectiva rompe com a tendência, própria das teses mainstream da sociologia económica, para enfatizar a influência social no mercado e, no mesmo passo, subestimar a influência do mercado na sociedade. Acreditar que a trajectória do avanço tecnológico e do mercado correspondem a um suposto desenvolvimento da racionalidade na história, e que a expansão do mecanismo do mercado não implica consequências sociais dramáticas mais não significa do que aceitar um novo tipo de fatalismo e as ilusões que ajudam a suster a sociedade de mercado na actual fase neoliberal.

O texto está organizado em quatro secções. A primeira expõe o contexto de mobilização da inovação, os seus antecedentes e a emergência da noção de inovação tecnológica com fins de comercialização. A segunda revela a passagem de uma visão negativa do novo até aos alvores da modernidade para uma visão favorável, já no século Xx. Argumenta-se que o prestígio recente do novo constitui o contexto cultural mais lato para a admissão acrítica da inovação e que na sua base se encontra o lastro da perspectiva moderna 
e historicista do progresso convertido hoje no que é aqui conceptualizado como "historicismo tecno-liberal". Na terceira secção, incide-se o olhar no estudo de Karl Polanyi com o estatuto de clássico, $A$ grande transformação (2012 [1944]). A estratégia é recuperar o sentido da sua tese acerca da tendência, impulsionada pelo liberalismo económico, para a subordinação da sociedade à força e magnitude do mecanismo de mercado como base para o entendimento da vaga de "inovação desincrustada" ao serviço dos gigantes tecnológicos e empresariais, que se tem vindo a desenvolver nas últimas décadas. A quarta secção analisa a continuidade daquela dinâmica através da extensão de produção abundante de "mercadorias fictícias" em âmbitos social e ecologicamente cruciais, tais como os do conhecimento, da comunicação humana, sociabilidade, trabalho, vida biológica, saúde e alimentação. $\mathrm{O}$ artigo conclui com a sustentação da ideia de que a inovação não deve ser considerada uma panaceia para todos os problemas, não deve ser orientada por meros propósitos de comercialização e é necessária a sua avaliação e regulação ética, política, social e ambiental.

\section{Mobilização para a inovação}

É sob o panorama amplo dos efeitos do choque da crise petrolífera dos anos 1970, da ascensão nos anos 1980 das doutrinas do liberalismo de mercado - conhecidas sob as etiquetas do thatcherismo, reaganismo, neoliberalismo e "consenso de Washington" -, do fim da Guerra Fria nos inícios dos anos 1990 e da formação de um mercado planetário mais interligado, que a inovação começou a ser abraçada como um conceito básico da política económica e se afirmou a expressão inovação tecnológica. Desde então, a inovação tem vindo a ser uma ideia central que aponta uma orientação para as economias, empresas, indústrias, universidades e para os campos da ciência e da tecnologia. A intervenção estatal em todo o mundo dito desenvolvido ou em desenvolvimento empenhou-se, emanando directrizes, formando entidades promotoras e investindo com fundos, na implementação da inovação. Um novo activismo foi estimulado, abrangendo campanhas, feiras, concursos e propaganda, que perseguem a criação de novidades, geralmente com forte carácter ou intervenção tecnológica. Slogans vanguardistas são evocados com frequência a favor da revolução permanente de actividades, matérias-primas, tecnologias, indústrias, formas laborais, profissões estabelecidas e mercados. Embora seja incentivada nos mais diversos planos, a maior enfâse tem sido na inovação tecnológica com potencial comercial, considerada um factor fundamental do aumento da produtividade e da busca de maiores lucros. É extraordinária a atenção prestada às conquistas tecnológicas, ao papel das grandes corporações no incremento tecnológico, às vantagens 
e ganhos que as empresas podem ter em termos de economização da força e custos de trabalho, aos mercados das tecnologias e aos encadeamentos da tecnologia com o comércio mundial. É saudada a suposta ou real ultrapassagem das tecnologias anteriores, votadas a uma sentença de obsolescência programada, assim como o papel que as novidades tecnológicas desempenham na transformação do mundo social.

No quadro desta cruzada pela inovação, formou-se igualmente um novo campo de pesquisa no meio universitário e científico, designado por "estudos de inovação", bem como uma vasta bibliografia académica que abrange um conjunto de handbooks, expondo modelos e teorias da inovação, o mais das vezes virados ou para a relevância do desenvolvimento do factor técnico e económico ou, em casos mais raros, para a importância das condições sociais e culturais, mas quase sempre com escassa reflexão crítica. ${ }^{1}$ Além desses handbooks, constata-se também a publicação de um acervo muito considerável de obras das mais variadas áreas, da economia às engenharias, da gestão à sociologia, em que a inovação é com frequência abordada segundo o princípio do mercado. ${ }^{2}$

É importante notar que, enquanto orientação dos governos, foi sobretudo após a Segunda Guerra Mundial que começaram a ser claramente abandonados os obstáculos à inovação e que foram concebidas noções favoráveis à mesma enquanto instrumento de acção económica dirigida, em parte ou na sua totalidade, por valores e objectivos de produtividade e lucros. É certo que o capitalismo de mercado esteve sempre associado à invenção de novas tecnologias para produzir mais mercadorias com menores custos de trabalho, maior disciplina da força laboral e em busca de maiores lucros. No entanto, a viragem cada vez mais favorável à inovação, no século Xx, foi particularmente anunciada nas teses formuladas, nos começos da década de 1940, por Joseph Schumpeter (1996: 125), segundo as quais a inovação criativa, destruidora do equilíbrio rotineiro, seria endógena e fundamental ao desenvolvimento económico, e não uma condição externa.

\footnotetext{
${ }^{1}$ A literatura respeitante à inovação, reveladora da aposta das entidades políticas, económicas e universitárias, cresceu ao ritmo do incentivo que lhe foi dado como orientação para as sociedades. Uma lista dos mais destacados handbooks publicados na última década inclui: Hall e Rosenberg (2010); Osterwalder e Pigneur (2010); Smits et al. (2010); Audrestsch et al. (2011); Kwok e Grondzik (2011); Lundvall et al. (2011); Arena et al. (2012); Mumford (2012); Rooney et al. (2012); Dodgson et al. (2013); Gault (2013); Moulaert et al. (2013); Redford (2013).

2 Ver Stoneman (1995, 2010); von Hippel (2006, 2017); Dodgson et al. (2008); Etzkowitz (2008); Van de Ven et al. (2008); Swann (2009, 2014); Verganti (2009); Fernández Pérez e Rose (2010); Archibugi e Filippetti (2011); Karlsson et al. (2012); Lerner e Stern (2012); Sveiby et al. (2012); Teece (2012); Fagerberg et al. (2013); Brynjolfsson e McAfee (2014); Dolata (2014); Engel (2014); Mohr et al. (2014); Mazzucato e Penna (2015); Niwa (2016); Schilling (2017); Schwab (2017); Chaminade et al. (2018).
} 
"A eterna tempestade da destruição criadora", escreveu, "é o facto essencial do capitalismo", tendo como actor central o "empresário inovador" (Schumpeter, 1976 [1942]: 87; tradução do autor). Para o economista austríaco, o empresário inovador é o responsável por novos produtos para o mercado, por meio de combinações mais eficientes dos factores de produção. As inovações dos empresários são consideradas motores do crescimento económico a longo prazo, no qual novos produtos destroem velhas empresas e modelos de negócio.

Mas ficando-se a dever a Schumpeter a introdução da inovação na teoria económica, como maior ou menor viés tecnológico segundo os seus intérpretes, ele não cunhou a expressão "inovação tecnológica" e ainda menos a analisou com detalhe. Tal denominação só surge após 1950 através de Rupert W. Maclaurin, historiador económico do Massachusetts Institute of Technology, que pode ser destacado como o primeiro teórico em inovação tecnológica nos finais de 1940 e inícios de 1950, embora continue a ser bastante ignorado nos estudos sobre as origens dessa inovação. Não apenas Maclaurin utiliza desde cedo a designação "inovação tecnológica", como a desenvolve enquanto processo sequencial no tempo, com início na investigação científica e cujo último estádio é a comercialização. Numa questão de décadas, a inovação tecnológica eclipsou outros termos e tornou-se a representação predominante da inovação (Godin, 2008).

Em finais do século Xx, a política científica e tecnológica fundiu-se com a política de inovação e indicadores de ciência e tecnologia foram redesenhados como parâmetros de inovação. Irrompeu então a linguagem da investigação e do desenvolvimento (I\&D) para definir o complexo que foi estabelecido entre a indústria e a investigação científica e tecnológica ao serviço da inovação comercial. Tal complexo foi identificado como uma alavanca da rotinização da inovação em todas as áreas possíveis na procura de novas frentes industriais, de comercialização, de ganhos de produtividade e de controlo do mundo laboral. O chamado modelo linear da inovação impôs-se como um processo sequenciado de fases, actividades e eventos com início na ciência ou na investigação básica e terminando no mercado (nacional e global). Nessa sequência, foram criadas agências de inovação para promover essa mesma inovação; estabeleceram-se prioridades de financiamento para favorecer as investigações com maiores possibilidades de originar inovações; instituíram-se incentivos económicos para investigações realizadas em contexto empresarial; e valorizou-se a obtenção de patentes por parte dos investigadores. Em todos esses esforços, os governos bem como entidades supranacionais - como a União Europeia - e de alcance mundial - como a OCDE e o Banco Mundial - foram apoiados por sectores 
académicos enquanto consultores que imaginaram modelos de inovação como um meio para enquadrar e guiar políticas (entre outros, ver Barbosa, 2011; Fernández-Esquinas, 2012; Garcia, 2012; Godin e Vinck, 2017). ${ }^{3}$

\section{Inovação como novo historicismo - O historicismo tecno-liberal}

Se, no presente, a inovação tem uma conotação claramente positiva, se é uma orientação política encorajada e patrocinada, se os inovadores são louvados, a pretensão ao novo teve no passado uma carga de suspeição, foi vista como perturbadora da ordem social e quem buscasse a novidade considerado indesejável. $\mathrm{O}$ actual sentido da palavra - quase incontestavelmente favorável à novidade - não deve, portanto, encobrir os diversos significados e fisionomias que teve nos séculos anteriores, e inclusive os deslizamentos que a ideia de novo teve no século Xx. Godin (2016 [2014]), autor de um robusto estudo sobre a representação histórica da inovação, argumenta que esta noção está hoje de tal modo ligada a uma ideologia económica que se descura ter sido durante séculos uma noção de cunho político contestada.

A abordagem de Godin é toda uma tentativa de afastar a noção de inovação da presente mitificação, começando por revelar como o próprio termo é apenas um entre muitos outros usados para falar do novo e da acção de introduzir uma novidade. No seu trabalho, distingue duas "epistemes": uma primeira, que se estende da Reforma ao século XIX, período no qual a inovação era essencialmente rejeitada; e uma segunda, no século xx, precisamente quando a inovação alterou o seu significado e adquiriu um carácter de nobreza (Godin, 2016 [2014]). Note-se que esta demarcação feita pelo autor entre duas grandes lógicas não deve ser entendida como um quadro de tal maneira asfixiante que impediria reconhecer a sedução pelo novo e a assunção de criatividade noutros períodos, como são exemplos vários movimentos literários e culturais, técnicos e pioneiros da ciência desde o Renascimento até finais do século XVIII. ${ }^{4}$ Godin (ibidem) esclarece que apenas na segunda metade do século Xx é que a inovação se tornou uma verdadeira palavra de ordem, agrupando uma diversidade de outros termos

\footnotetext{
3 É fácil constatar que a literatura da inovação está saturada de modelos. Embora antes da década de 1960 o termo "modelos" tenha sido pouco usado, Godin (2017) sugere que esse termo tem tanto uma função científica quanto retórica.

${ }^{4}$ Relativamente à criação cultural e técnica, Hermínio Martins (2011: 85-86) refere a existência de paralelos teológico-científico-tecnológicos em que artistas e artesãos, desde o Renascimento, evocaram cooperações com a Divindade no quadro de uma cultura cristã que realçava a imagem de Deus como "criador de criadores". Isto permitiu a concepção de que artesãos, artistas ou engenheiros podiam criar como demiurgos, não ex nibilo, mas sobre materiais preexistentes, ampliando a potência disponível ao Homem e criando belezas inéditas.
} 
e conceitos, embora a expressão "inovação tecnológica" tenha passado a ocupar quase toda a extensão semântica da novidade."

A apologia do novo - ou "neolatria" - das últimas décadas pode então ser compreendida como ressonância do espírito progressista nascido da consciência moderna, para o qual foi decisivo o triunfo de uma nova noção de tempo histórico voltado para o futuro e aberto à novidade e à mudança. Convém aprofundar esta questão. $\mathrm{Na}$ Antiguidade pagã predominava a valorização do passado, paralelamente à ideia de um presente decadente; na Idade Média o presente estava encerrado entre o peso do passado e a esperança num futuro escatológico; e no mundo moderno em formação desde o Renascimento surge um novo conceito de tempo que o remete para o futuro. As explorações marítimas e a formação do conhecimento científico dos séculos XV, XVI e XVII, conjugados mais tarde com a revolução industrial, o processo de produção em massa e a expansão económica, serviram de alento à afirmação da superioridade dos modernos sobre os antigos e de alicerce de uma consciência histórica direccionada para o devir. Nos séculos XVIII e XIX, certas expressões de desenvolvimento social e um novo conjunto de ideias estruturantes permitiram rasgar horizontes e negar o fatalismo nas relações entre os homens e na relação destes com a natureza e com Deus, as quais eram próprias da mentalidade europeia. A ideia de que o ser humano era livre para determinar o rumo da sua própria vida, a confiança na inteligibilidade da realidade e na faculdade autónoma da razão para a tornar evidente, bem como a crença na predisposição da humanidade para a perfectibilidade, contribuíram para compor a noção de progresso que se foi impondo na Europa.

No contexto descrito, o sentido da história irrompeu como problema, e uma filosofia da história pôde ser formulada enquanto execução de um plano sequenciado, grandioso e benévolo, cujo fim determinado era o engrandecimento da humanidade. Para muitos sistemas de pensamento influentes da época, na qual se destaca o hegeliano e a sua ideia da conquista do tempo histórico pela razão, a história surge regida por um desígnio último de melhoramentos seguros e contínuos, inscrito numa

\footnotetext{
${ }^{5}$ A este respeito caberia também lembrar o papel do futurismo, com início antes da Primeira Guerra Mundial por escritores e artistas italianos, mas com influxos posteriores noutros contextos, tendo sido uma vanguarda cultural laudatória tanto do novo como do novo tecnológico. Para os futuristas italianos, o locus primordial dos valores estéticos era fundamentalmente o futuro, e não a natureza ou a arte do passado, o qual era projectado e sublimado como um mundo em processo de mecanização da existência. Os futuristas italianos foram veículos da "neolatria" em versão tecnocrática. A sua glorificação do novo acompanhava a glorificação da tecnologia, incluindo a que estava associada à guerra. Bons apontamentos sobre esta questão encontram-se em Berman (1982) e Martins (2011: 152-155).
} 
dinâmica ascendente da racionalidade que vem do passado para o presente. Os europeus modernos seriam os actores principais do progresso e os antagonismos, padecimentos e tormentos vividos pela humanidade representariam apenas meros estorvos na sua marcha ascendente. A libertação dos seres humanos aparecia conforme os imperativos da história, imperativos que se reconheciam, afinal, como no passado se reconhecia a vontade de Deus.

O entendimento do processo histórico como seguindo um encadeamento ou direcção especial, concomitante à racionalidade, abrangendo diversas variantes, é conhecido sob a designação de "historicismo". ${ }^{6}$ O conceito que neste texto é adoptado define-o como uma representação do tempo histórico de tipo determinístico, na qual todos os acontecimentos históricos aparecem como obedecendo a leis ou tendências mais ou menos rígidas. São muitos os críticos do historicismo assim entendido, no século XX, havendo um largo consenso acerca da rejeição de qualquer visão do curso da história em que esta figure como o cumprimento de um plano ou de um programa. ${ }^{7}$ Em traços largos, o tipo de historicismo professado por muitas visões modernas da ideia de progresso tendeu a conceber a história no seu conjunto como um fio evolutivo, acumulativo, ascendente e teleológico de padrão racional, cujas leis conduzem irresistivelmente a humanidade para o futuro. Essas leis podiam ser descobertas, tornando possível condicionar decisivamente - ou mesmo determinar - a direcção da acção política e social. O "historicismo" valoriza o presente como sendo superior ao passado, justifica-o como prenúncio do futuro e celebra a novidade

\footnotetext{
${ }^{6}$ Um entendimento anterior do historicismo concerne a concepção, surgida em meados do século XIX por parte de pensadores alemães, nos quais se destaca Dilthey, defensora de que o conhecimento da sociedade e da condição humana tem um carácter intrinsecamente histórico, sendo por isso necessária uma aproximação filosófica do conhecimento histórico. Esta tendência caracteriza-se pela recusa dos modelos cientificistas do conhecimento e propunha a sua substituição por modelos históricos, enraizados em contextos concretos e de tipo perspectivístico e interpretativo, aplicáveis não apenas à história, mas também à economia, ao direito, à teoria política e a grandes domínios da filosofia. Croce e Collingwood são apontados como figuras destacadas desta perspectiva original do historicismo.

${ }^{7}$ É muito comum referir como expoentes da crítica ao historicismo pensadores liberais como Karl Popper (1957) e Isaiah Berlin (1954) e a crítica ao historicismo como uma espécie de prerrogativa liberal e de confinamento do historicismo, no campo das correntes políticas, ao progressismo socialista e comunista. Esta tendência tem contribuído provavelmente para negligenciar que em muito progressismo liberal dos séculos XIX e XX se encontra um atraente historicismo. Tal situação leva também a esquecer trabalhos intelectuais relevantes que poderão ser incluídos na reflexão crítica do historicismo, de que são expoentes Reinhart Koselleck (1988 [1959]; 2004 [1979]), Ernest Gellner (1992), Fernando Catroga (2009) na literatura portuguesa, e no próprio campo do marxismo, Henri Lefebvre (1970). É verdade, no entanto, que as correntes socialistas e comunistas, ao longo século xx, com escassas excepções, se distinguiram por uma fé inabalável relativamente ao progresso da humanidade.
} 
- ou suposta novidade por si criada - como um passo para atingir o horizonte de perspectivas construídas. Como se percebe, é legítimo inserir a actual visão da inovação na moldura mental do historicismo. Também a inovação tem sido entendida como uma dinâmica irrevogável da racionalidade, que transmite a impressão de nos estar a levar para o futuro; benéfica ainda, porque seria fruto de uma tendência histórica de progresso, em particular porque adstrito ao progresso tecnológico; e finalmente de mudança, pois assoma como uma força que pode ser guiada pela acção humana rumo à grandeza e libertação da humanidade.

À luz das considerações tecidas, é possível sustentar que o sentido hegemónico actualmente favorável à inovação comercial está impregnado do temperamento historicista, por via do qual a consagração do novo é agora conjugada, não com a história, mas com a tecnologia e também com o mercado. Significa isto que o historicismo não esgotou a potência semântica com a retracção que sofreu no campo da historiografia dos séculos XX e XXI. Um conceito adequado ao fenómeno da inovação tecnológica começa por ser o de "historicismo tecnológico" para designar a ideia de que as novidades da tecnologia aparecem como uma expressão de um itinerário racional e inexorável de evolução da razão - identificada como razão técnica -, de tal modo que só podem ser consentidas e adoptadas sem hesitações. As conquistas tecnológicas aparecem, então, como a força que torna activa a realização - por parte dos seres humanos - das suas aspirações. Nesta óptica, as tecnologias do presente são sempre estimadas como superadoras de muitas dificuldades humanas do passado. $\mathrm{O}$ voluntarismo tecnológico instala-se e a mudança tecnológica é enaltecida. Entretanto, tendo em conta que este historicismo tecnológico tem correspondência com o entendimento hoje hegemónico da tecnologia como mercadoria e do mercado como resultado natural de uma evolução crescente da razão - em termos de sistema produtivo e circulação de bens -, afigura-se mais adequado falar de um historicismo que é tanto tecnológico como mercadológico. A este novo historicismo "tecno-liberal" subjaz um entendimento da história da tecnologia e do sistema de produção e distribuição identificados com uma perspectiva linear, redutora e finalista do desenvolvimento histórico da razão - as tecnologias modernas e o mercado auto-regulado seriam, cada uma por si, resultado de uma lógica coerente cujo sentido conduz à grandeza progressiva da humanidade. Por conseguinte, à humanidade cabe principalmente acolher, com maior ou menor adesão e com este ou aquele uso, a inovação tecnológica comercial. A tecnologia e o mercado seriam os novos dínamos da história. Acompanhar a inovação tecnológica comercial converte-se, assim, numa nova inevitabilidade histórica. 
Optimismo histórico, optimismo tecnológico e optimismo mercadológico conjugam-se no historicismo tecno-liberal. ${ }^{8}$

Ao invés de festejar este cenário encantador, é necessário deixar de ver a tecnologia sob esta representação, como se cumprisse uma exigência interna e correspondesse a um itinerário que antecipa o esperado. Em alternativa, há que compreendê-la como o resultado de um processo onde interferem, é certo, avanços nos conhecimentos científicos e tecnológicos, mas também apostas económicas, sociais e propósitos comerciais, conflitos, interacções imprevistas, possíveis formas criativas de usos, efeitos imprevisíveis da acção humana, entre outras condições que não aconselham uma perspectiva ingénua do suposto trajecto racional do avanço tecnológico e das consequências do aumento das capacidades científicas e tecnológicas. No fundo, é necessário desprender-nos das amarras deste novo historicismo para ter uma atitude reflexiva do que se joga na actual política da inovação e dos processos paralelos de mudança na esfera científica e tecnológica, hoje completamente entrosados com as "revoluções industriais", já anunciadas e por anunciar, e a expansão e aprofundamento da economia de mercado e das grandes corporações.

\section{A grande transformação do século xıx e o mecanismo do processo capitalista}

A abertura ao novo e a ideia moderna de progresso integra o mesmo complexo histórico da Revolução Industrial e da introdução de máquinas que começaram a permitir a produção em grandes quantidades, implicando todo um contexto diferente em termos de investimento, factores de produção, matérias-primas, circulação e aquisição dos produtos fabricados. É nesse contexto que se estabelece a economia de mercado a partir do século XIX e o mecanismo do processo capitalista. Só a renúncia ao enredo do historicismo tecno-mercantil pode permitir desbravar o sentido político e social da introdução sistemática de novas tecnologias e a sua interacção com o desenvolvimento desse mecanismo.

Uma boa introdução ao processo enunciado encontra-se na celebrada obra de Karl Polanyi, A grande transformação (2012 [1944]), atenta à formação da economia de mercado, suas implicações e desenvolvimentos. Este estudo permite não só uma leitura - já bastante realizada - de como a sociedade passou a estar submetida à influência penetrante

\footnotetext{
${ }^{8}$ As minhas primeiras incursões na conceptualização da inovação como expressão historicista, embora sem nomear o conceito de historicismo tecnológico e historicismo tecno-mercadológico, encontram-se em Garcia (2012). Martins (2011) refere o conceito de historicismo tecnológico no quadro de outra problemática.
} 
de uma esfera económica que então emergiu, de modo demarcado da restante vida social, como uma outra - que quase não tem merecido atenção - da relação entre a introdução de novos meios de produção e a dinâmica de um processo produtivo que passa a estar organizado na forma de compra e venda própria do sistema mercantil. A argumentação de Polanyi é de extrema pertinência para fornecer pistas e compreender a mudança assombrosa que tem ocorrido, desde finais do século Xx, sob o incitamento para a inovação em domínios tão sensíveis para a vida social, política, cultural e para o mundo natural como os que se têm observado no conhecimento, na comunicação, na sociabilidade e no trabalho, possibilitada pelas ciências dos computadores, tecnologias da informação e inteligência artificial, e na esfera da vida biológica, da saúde e da alimentação, pelas biotecnologias moleculares.

As principais teses de $A$ grande transformação são bem conhecidas e têm sido bastante discutidas, razão pela qual delas se fará aqui apenas uma síntese, mas dando uma especial atenção aos efeitos da introdução dos novos meios mecânicos na esfera produtiva. Focalizando a Inglaterra da transição entre o período pré-industrial e o da industrialização, Polanyi demonstra como a intervenção estatal, influenciada pelo liberalismo económico, se empenhou num movimento de alteração dos anteriores mercados isolados e regulamentados num sistema de mercados auto-regulados, ou seja, baseados apenas na troca competitiva e no lucro. Tendo uma existência ancestral, os antigos mercados eram constituintes de determinadas localizações sociais com as suas normas morais, laborais e religiosas. A construção de mercados de âmbito nacional e depois internacional resultou, não da própria dinâmica dos mercados, mas da acção deliberada do Estado. Os novos mercados foram instituídos como mecanismos auto-regulados segundo o princípio de que os domínios da produção e da distribuição dos bens são controlados, regulados e dirigidos apenas pelos preços de mercado. Só sob a sua própria regulação é que os mercados seriam bem regulados. O jogo livre entre a oferta e a procura era visto como uma acção natural que levaria à maximização de todas as partes. Segundo Polanyi, deve-se à dinâmica destes novos mercados a divisão institucional da sociedade numa esfera económica e numa esfera política, divisão esta que constituiu uma "inovação singular" (Polanyi, 2012 [1944]: 214).

Para fundamentar o carácter excepcional daquela situação, Polanyi apoiou-se em dados antropológicos e historiográficos, argumentando que aquela diferenciação não existia historicamente na sociedade, nem sob as condições da tribo, nem sob as do feudalismo, nem sob as do mercantilismo. 
Em consequência, se normalmente a ordem económica era simplesmente uma das funções da ordem social, nas sociedades sujeitas a uma economia de mercado auto-regulado a tendência passou a ser para a ordem social ficar muito condicionado pela lógica própria, grande magnitude e poder desse sistema (ibidem). Tal traduziu-se, nomeadamente, no facto de que bens como a terra, o trabalho humano e o dinheiro, que antes de serem integrados no mercado se encontravam apenas inscritos na ordem social, terem sido convertidos em elementos da troca mercantil. Para Polanyi, esta deve ser considerada uma diferença decisiva relativamente às sociedades anteriores à formação da economia de mercado.

Coloca-se, assim, o problema das relações entre economia e sociedade, que é equacionado por Polanyi através da ideia de "incrustação" (embeddedness). Esta talvez tenha sido inspirada na metáfora do carvão incrustado nas paredes de rocha das minas, fruto das suas leituras da história económica da Inglaterra (Block, 2012: 89). Numa passagem muito conhecida, o autor afirma:

O controlo do sistema económico pelo mercado [...] significa nada menos do que a direção da sociedade como um elemento auxiliar do mercado. Em vez de existir uma economia incrustada (embedded) nas relações sociais, são as relações sociais que são incrustadas no sistema económico. A importância vital do fator económico na existência da sociedade exclui qualquer outro resultado. (Polanyi, 2012 [1944]: 194)

Por outras palavras, o domínio do sistema produtivo e distributivo por parte do mecanismo do mercado, em situação de auto-regulação, implica que a economia fique submetida à sua poderosa influência e do mesmo modo a sociedade à economia. No plano epistemológico, o conceito estabelece que a economia, incluindo o mercado, não pode deixar de estar sob a influência constante da sociabilidade (socialização cultural, intercâmbios de reciprocidade, sistemas de estatuto formal e informal, redes sociais, confiança), das relações de poder (hierarquias, posse de capitais) e da contingência (consequências imprevistas da acção racional, incerteza). O mesmo é dizer que o poder do mercado não é idêntico a uma predestinação social. Já no plano da análise histórico-social, "incrustação" remete para a situação concreta de sociedades que estão sujeitas à influência avassaladora de economias de mercado compassivas com a desregulamentação. Este entendimento do conceito de incrustação contraria a posição preponderante da "nova sociologia económica" que, assinalando bem que o mercado é uma entidade social e sujeita à sociabilidade, tende 
a assimilar o mercado à sociedade. ${ }^{9}$ É evidentemente errado não ter em conta as interacções sociais que decorrem no mercado e as redes por aquelas criadas com as suas expectativas, afinidades, animosidades e conflitos. Mas também é equivocado não considerar que as relações entre as pessoas e entre estas e a natureza se modificam quando tomam a forma de relações de mercado ou ainda não atender a que o valor de mercado pode ofuscar ou até suprimir os valores morais de bens e actividades humanas e sociais. Por um lado, a ideia de "incrustação" indica que é a sociedade que dá à economia um sentido e um fim, e não a economia à sociedade, por outro, que o mercado se tornou um grande factor de estruturação social cujo mecanismo, quando sem limites, altera intensamente a substância da própria sociedade e as relações com a natureza. ${ }^{10}$

Compreende-se assim a ideia de Polanyi segundo a qual o projecto de uma economia de mercado inteiramente auto-regulada não é mais do que um desígnio utópico do pensamento económico e político liberal. As orientações que procuram desenvolver uma maior autonomia do mercado provocam consequências sociais tão destruidoras que acabam por conduzir à necessidade da intervenção regulatória por parte dos governos. O que Polanyi critica com a metáfora da incrustação é a crença liberal de que possa existir uma sociedade plenamente baseada em ou subordinada a mercados sem restrições, isto é, assentes simplesmente na compra e venda e na motivação do lucro de todos os âmbitos que possam entrar na cadeia produtiva industrial e distributiva. Uma "desincrustação" da economia em relação à sociedade não pode, pois, designar uma possibilidade real, mas tão-só um cometimento em que os esforços para expandir o mercado sem entraves aumentam a tensão social e levam à necessidade de intervenção regulatória do Estado.

\footnotetext{
9 A negação do constrangimento que o mecanismo de mercado per se produz no mundo social à luz da noção de que ele não é outra coisa do que uma entidade social pode ter a sua raiz na noção muito arreigada em várias correntes sociológicas de que mais nada conta para compreender e explicar o mundo social senão as relações sociais, a sociabilidade ou a influência social. Esta é uma perspectiva epistemológica que, nas versões mais extremas, desvaloriza modos de existência e de interferência causal na realidade social que não sejam estritamente sociais. A corrente mais influente da "nova sociologia económica" pode ser incluída nessa tendência porventura na procura de afirmação de um estatuto científico para a investigação sociológica das economias de mercado. Para uma discussão sobre este tópico, ver: Granovetter, 1985; Swedberg, 2003; Block, 2005, 2012; Portes, 2010; Mingione, 2011; Curto et al., 2012; Santos, 2012.

${ }^{10}$ A este respeito, vale a pena salientar que o Prémio Nobel da Economia, Joseph Stiglitz, argumenta que o conceito de incrustação de Polanyi indicava que este "via a economia de mercado, não como um fim em si própria, mas como um meio em vista de fins mais fundamentais" (Stiglitz in Polanyi, 2012: 77). Fred Block partilha do mesmo tipo de posição: para este autor, "o termo 'incrustação' exprime a ideia de que a economia não é autónoma, como a teoria económica quer que ela seja necessariamente, mas está subordinada à ação da política, da religião e das relações sociais" (Block in Polanyi, 2012: 89).
} 
Veja-se, de seguida, a concepção de Polanyi sobre o papel exercido no mecanismo do mercado moderno por parte dos novos meios mecânicos com grande capacidade de produção, que emergiram durante a era industrial. Para o autor, a transformação decisiva que constituiu o estabelecimento da economia de mercado e a natureza desta instituição só podem ser plenamente apreendidas tendo em consideração, usando os seus termos, "o impacto da máquina”, da "utilização de máquinas especializadas", da "maquinaria complexa", numa sociedade - a Inglaterra do século XIX - que estava já envolvida no alargamento do comércio, quer à escala nacional, quer internacional (Polanyi, 2012 [1944]: 171-172). Transposto para o nosso tempo, trata-se, pois, da questão da interacção entre os novos sistemas científico-tecnológicos de produção e um sistema económico em que a esfera produtiva está organizada na forma da compra e venda. Saliente-se que a aclaração de Polanyi não sustenta que foram as invenções mecânicas que criaram o sistema de mercado, mas sim que elas foram uma condição capital (ibidem: 172).

Importa, a este respeito, seguir as suas palavras de muito perto. Sendo a economia de mercado um sistema económico controlado, regulado e dirigido pelos preços de mercado, é a este mecanismo que é delegada a definição da ordem nos domínios da produção e da distribuição dos bens. Tal economia baseia-se na expectativa de que os seres humanos se comportem de forma a alcançar um máximo de lucro possível. Aquele mecanismo é, já se viu, um mecanismo de auto-regulação, que implica que toda a produção tenha como fito ser vendida no mercado e que todos os rendimentos decorrem dessa venda. Foi deste modo que passaram a existir mercados para todos os elementos que entram no processo industrial, não só para os bens, incluindo os serviços, mas também para o trabalho, a terra e o dinheiro, e os preços correspondentes denominam-se preço das mercadorias, salários, rendas e juros (ibidem: 210). Compreende-se, desta maneira, que o mercado tenha absorvido várias áreas da esfera produtiva e da distribuição da sociedade como factores de produção, tais como bens naturais (a terra), bens da vida humana (o trabalho) e meios de troca (o dinheiro), assim ampliando o seu domínio. Isto aconteceu porque, como argumenta Polanyi, "a extensão do mecanismo do mercado aos elementos da indústria - trabalho, terra e moeda - foi a consequência inevitável da introdução do sistema da fábrica numa sociedade comercial. Era necessário que os elementos da indústria fossem postos à venda" (ibidem: 219). Bens que não foram produzidos para serem comprados ou vendidos e que, segundo a definição empírica de mercadoria, não eram mercadorias, ao serem anexados no mercado, passaram a ter um valor ditado pela troca mercantil e converteram-se em "mercadorias fictícias" (ibidem: 214). 
Por tudo o que se disse, o mecanismo do mercado e a sua ligação com a produção industrializada, aceitando a tese polanyiana, manifesta-se como procura incessante de apreensão de mais e mais elementos passíveis de entrar na cadeia produtiva e mercantil, de modo a ampliar a quantidade e a diversidade de mercadorias e os lucros, buscando em simultâneo economizar os custos do trabalho e disciplinar a força laboral, todo este caminho aberto pela introdução de novos e mais potentes meios tecnológicos de produção. O que integrava a vida humana, social e natural é transmutado em factor de produção, sujeito à compra e venda e, portanto, adquire a forma de mercadoria, destinada a ser consumida e a gerar mais dinheiro do que aquele que foi investido. Sob a condução do liberalismo económico favorável a um sistema económico baseado apenas na auto-regulação mercantil, este processo de produção é, logicamente, uma forma de espoliação progressiva da natureza, da vida humana, do trabalho, das formas de conhecimento, do próprio desenvolvimento tecnológico e de tudo o que possa ser transfigurado em meras vias para produzir lucro através do consumo de produtos e serviços. Ao implicar o incitamento ao consumismo ou como forma de obter altas taxas de lucro, é vital que a ficção da mercadoria abranja também o próprio dinheiro através da produção de especulação financeira, monetária e do crédito, e daí a importância que foram assumindo os mercados financeiros e o capitalismo financeiro.

\section{Inovação desincrustada}

Sob o pano de fundo do mecanismo descrito, a inovação tem sido - mesmo quando a palavra não existia e não era uma política económica instituída uma disposição de reinvenção industrial e de todo o tipo de serviços que procura na ciência e na tecnologia a provisão de um manancial de saberes e meios para a reprodução do próprio mecanismo. Acresce ainda que a inovação tem também tido como objectivo a criação de todo o género de armas e meios bélicos virados para o domínio político (e imperial). O que a inovação promovida desde a década de 1980 significou de diferente foi a sua própria institucionalização enquanto política económica e a determinação em reduzir continuamente a autonomia dos universos da ciência e da tecnologia para os converter plenamente num empreendimento em prol de mais e mais radicais reinvenções, ancoradas em promessas e utopias tecnológicas, para objectivos de produtividade, alterações no trabalho e rentabilidade económica. Essa política tem sido conjugada igualmente com a reinvenção financeira como agente fundamental na especulação do próprio capital e no consumo enquanto antecipação de lucros. A inovação tem sido um instrumento político que activa a invenção e a introdução de novidades 
no âmbito económico, de modo praticamente irrestrito, tanto nas áreas já existentes como em novas áreas, sempre segundo o princípio de que só à lógica de mercado cabe definir que opções deverão prevalecer. Trata-se, pois, de uma inovação cujo intuito fundamental é o lucro, uma inovação que continua a lógica da desincrustação da economia da sociedade, mas agora de modo acelerado e exacerbado - uma "inovação desincrustada", para usar a noção polanyiana. Isto porque tal como é a sociedade que dá sentido e fim à economia, também é a sociedade que deve dar significado e propósito à inovação, e não o contrário.

Sob o alinhamento do projecto de inovação das últimas décadas, a conjuntura dos nossos dias pode ser interpretada à luz da transformação de uma "economia do trabalho" para uma "economia do conhecimento" (Powell e Snellman, 2004; Murteira, 2004; Rooney et al., 2012; Sveiby et al., 2012), ou da transição para um "capitalismo cognitivo" (Fumagalli e Lucarelli, 2007; Moulier-Boutang, 2011; Vercellone, 2005; Lazzarato, 2014; Pasquinelli, 2015), dada a crescente intensidade do factor cognitivo envolvido nos processos de produção, distribuição e recepção, bem como nos produtos, serviços e inclusivamente fontes de abastecimento, ou ainda para um "capitalismo digital" (Schiller, 1999; Picciano e Spring, 2012; Fuchs e Mosco, 2015), uma vez que o elemento cognitivo está cada vez mais a ser incorporado na tecnologia digital. Colocam-se, de seguida, sob o escrutínio crítico três facetas cardeais da inovação.

A referência a uma economia do conhecimento ou, mais adequadamente, a um capitalismo cognitivo/digital, procura dar conta da inscrição da ciência e da tecnologia, e a própria interpenetração destas duas esferas, bem como de outros saberes e faculdades, na criação de valor económico e na competição dos mercados enquanto tendência ideológica e realidade concreta desde finais do século Xx. Esta conformação da ciência e do desenvolvimento tecnológico é a primeira das questões críticas que é indispensável apontar e chegou a ter, na década de 1990, uma formulação bastante saudada e acolhida pelo mainstream universitário: a chamada "tripla hélix", uma expressão usada por Etzkowitz e Leydesdorff (1995) para apelidar a aliança entre a universidade, a indústria e o governo relativamente à inovação em acção. Não obstante a ausência de suficientes estudos documentados que apontem o sentido das mudanças de reconfiguração dos campos científico e tecnológico quanto à sua incorporação na esfera industrial e comercial em áreas como a das ciências dos computadores, Internet e digital, e ciências biológicas e da saúde -, existem indicações consideráveis da anexação destas nos objectivos industriais, na lógica empresarial e comercial, assim como de alterações importantes no estatuto e mandato dos investigadores, 
vivendo cada vez mais sob a imposição de se transformarem em produtores de mercadorias. ${ }^{11} \mathrm{~A}$ propriedade intelectual sob a forma de patentes cumpre aqui um papel de primeiro plano. Note-se, porém, que o factor cognitivo não se restringe apenas à mobilização (e privatização e expropriação) do conhecimento científico e do conhecimento tecnológico, envolvendo outros como o design, o estético, o marketing, o estudo dos mercados e dos consumidores, bem como os recursos comunicacionais e imaginativos da força de trabalho e de outros criadores potenciais. Ainda neste âmbito, uma consequência extremamente negativa das políticas de inovação é marginalizarem as áreas de investigação menos susceptíveis de potencial inovador segundo uma lógica tecnológica e mercantil, de que são exemplos a investigação fundamental, as humanidades, vários problemas ambientais, as incertezas associadas às tecnologias, as formas de agricultura alternativa e o melhoramento das condições de vida e de saúde das populações mais carenciadas.

Um segundo factor crítico da política para a inovação diz respeito à abertura ao sistema produtivo e ao processo de mercadorização de novos âmbitos, que não podiam antes ser inseridos nesse mecanismo por ausência de capacidade científica-tecnológica e de legitimação. É o caso das transformações em curso que estão a conduzir à constituição de novas áreas industriais e comerciais, distinguindo-se as que têm como base a noção de informação (computadores, digitalização, Internet, mas também biotecnologia, farmacêutica, alimentação, etc.). Os novos ramos industriais operam à escala global e conjugam o conhecimento científico-tecnológico, a apropriação da função de reprodução e o controlo cerrado sobre a distribuição e o uso para impedir a reprodução. ${ }^{12}$

Observa-se, neste período, a propensão para as inovações se associarem em cachos, abrangendo as áreas das ciências dos computadores, tecnologias da informação (software, Internet, smartphones, dados, tablets, ipads, gaming, novos media, inteligência artificial...) e biotecnociências (alimentos geneticamente modificados, melhoramento vegetal, genómica florestal, medicina genómica, procriação artificial, diagnóstico e aconselhamento genético, bioengenharia de tecidos, farmocogenómica...), entre outros campos. Os mercados de tecnologia, de informação, de dados, de imagens, os biomercados, passaram a ser, claramente, essenciais na actual economia

\footnotetext{
${ }_{11}$ A este respeito, ver, entre outros, Pestre (2003); Krimsky (2003); Garcia (2006); Garcia e Martins (2008); Nowotny et al. (2010).

12 Os conceitos de tecnologia profunda e inovação profunda assentam bem nesta realidade, quer por resultarem de domínios científicos de grande complexidade, quer pelo potencial para instigar vastas mudanças económicas e sociais. No entanto, também abrangem possibilidades de inovação incremental.
} 
de mercado, comandados pelos gigantes tecnológicos (Alphabet, Microsoft, Amazon, Apple, Facebook, Bayer, Novartis...). É possível afirmar que inúmeras formas de conhecimento, tecnologia, faculdades vitais dos seres humanos e formas de vida biológicas têm estado sujeitas a um cometimento de deslaçamento das suas ordenações sociais e da natureza.

Um caso exemplar de "inovação desincrustada" - muito discutido nos planos político, sociológico, filosófico e objecto de graves conflitos sociais - é o das sementes transgénicas e a sua disseminação em plantações e comercialização. Tradicionalmente, as sementes eram entidades biológicas renováveis e regenerativas constituintes de ecossistemas que geravam produtos predominantemente voltados para as necessidades locais, em consonância com a cultura e a organização social, tendo sido seleccionadas através de conhecimentos compartilhados pelos agricultores ao longo de séculos. Já as sementes transgénicas, nas quais a engenharia genética quebra a unidade da semente como fonte de uma colheita e simultaneamente reprodutora de si mesma, são mercadorias produzidas por empresas de capital intensivo que têm a sua patente e cujo objectivo é obter lucros no mercado mundial da alimentação. ${ }^{13}$ Tal como ocorreu com a terra, o trabalho e o dinheiro analisados por Polanyi, conhecimento científico, tecnologias, genes, genomas, entidades biológicas - através da capacidade tecnocientífica e da extensão dos direitos de propriedade intelectual e das patentes têm estado sujeitos à sua conversão em mercadorias "fictícias" de indústrias emergentes propulsionadoras de novos mercados.

Tudo indica ter sido decisivo o papel jogado pelas ciências dos computadores e pelas tecnologias da informação no quadro desta circunstância. O que possibilitou, em termos técnicos, aos agentes transnacionais e nacionais movimentarem-se no mercado global foi a existência de uma base instrumental em evolução constante, a qual garante o aumento da capacidade de recolher, reproduzir, tratar e transmitir informação de diversos tipos, assim como modificar profundamente as formas de produção e distribuição. Em toda a vasta área da economia digital há realmente que ter em conta o movimento de convergência entre as ciências dos computadores, as tecnologias da informação, a inteligência artificial e as biotecnociências. As infra-estruturas tecnológicas que sustentam o agrupamento das inovações dependem das capacidades de processamento dos computadores e do uso da Internet. Advém ainda que o desenvolvimento de campos tecnológicos e industriais - como o das tecnologias da informação, biotecnociências e da

${ }_{13}$ Nesta matéria, ver, entre outros, Kloppenburg (1988), Shiva (1997), Altieri (2001), Lacey (2005) e Garcia (2006). 
inteligência artificial - tem estimulado incessantemente novos ciclos de negócios, sendo que o primeiro desses âmbitos tem vindo a potenciar grandes alterações na produção, distribuição, consumo, formas laborais, modos de vida, formas de comunicação, conhecimento e de entretenimento. Não se trata, pois, de uma mudança tecnológica que possa ser considerada um mero prolongamento de tecnologias anteriores - a expressão adequada para a mencionar é de mudança tecnológica cesurial. O processo em curso de hegemonia digital, em associação com as projecções sobre a inteligência artificial e a robotização, está igualmente a favorecer - talvez mais relevante do que o espectro da substituição do trabalho ou as promessas de ganhos de produtividade - novas modalidades de desqualificação e fragilidade laboral (Caldas e Teles, 2019; Teles e Caldas, 2019).

Um terceiro factor crítico da concepção hegemónica de inovação concerne a disposição que pode ser denominada de "pseudo-inovação" e que remete para o investimento, sobretudo na dimensão estética dos produtos, conjugada com marketing e publicidade, de modo a conferir o valor de novo e original, enquanto estratégia de diferenciação de produto. Neste caso, a potencialidade estética de toda a realidade social é explorada em batalhas económicas que pressupõem a sujeição da sensibilidade e o consumismo. Muitos dos produtos tecnológicos das grandes empresas procuram acrescentar ao seu lado funcional características de tipo cultural que mobilizem o gosto e a sensibilidade para a produção de consumo. Esta inflexão estética da produção industrial indica que as empresas investem na criação incessante de novos bens para competir com os já existentes, utilizando-os no estímulo ao consumismo. ${ }^{14}$ Mostra ainda que muita inovação é, não propriamente incremental, mas superficial. Trata-se de uma óbvia sobreposição do valor de troca sobre o valor de uso, característica bem conhecida - apelidada de fetichismo da mercadoria - do capitalismo de mercado. O conceito aqui avançado de pseudo-inovação procura desvendar a camuflagem que encobre a domesticação da criatividade (Mould, 2018), os métodos de massificação, as operações de montagem e os cálculos de mercado que tiveram lugar no produto e visam a mobilização industrial do gosto e a compra. Tais métodos ficam ofuscados pela dimensão comunicativa ou cultural introjectada nos produtos, de modo a que apareçam sob uma reputação de criação. Os meandros mais recônditos das emoções, dos afectos e da cultura são capturados por realizações destinadas a serem um motor económico. Como

${ }_{14}$ O fundador e ex-director da revista Wired, David Rowan (2019), designa este tipo de inovação de "bullshit innovation". Alguns dos seus exemplos incluem cuecas anti-radiação, espremedores de sumo inúteis e ovos ligados à Internet. 
muitos autores têm sustentado, o actual modelo pós-industrial e pós-fordista, em que a informação e o conhecimento têm um papel crucial, está envolvido num movimento de culturalização da produção industrial (ver, entre outros, Assouly, 2008; Alonso Benito e Fernández Rodríguez, 2018). O mundo da criação e da produção artísticas terá antecipado o caminho para o os novos processos industriais. Se a bandeira da criatividade foi assimilada pela inovação tecnológica, então a industrialização do século Xx e a comercialização seguem as pisadas da industrialização da cultura.

\section{Conclusão}

$\mathrm{Na}$ tradição da economia política, na sua perspectiva crítica, esta reflexão dedicada ao conceito hegemónico de inovação procurou dar conta das relações sociais, em especial as relações de poder que dão corpo aos processos de produção, distribuição e consumo das sociedades. Ainda no quadro da mesma perspectiva, houve a preocupação de examinar os entrecruzamentos das áreas económica, política e social, bem como em estabelecer um compromisso com valores morais.

Tendo como objecto de análise a política de inovação, este artigo procurou demonstrar que a inovação tem sido essencialmente uma construção política dirigida para a busca incessante da produtividade e do lucro, através da extensão do mecanismo do mercado a novas esferas do mundo natural e da vida humana, como as do conhecimento, comunicação, trabalho, vida biológica, alimentação e saúde. Deu conta do enviesamento tecnológico da política de inovação em duas dimensões: por um lado, a aceleração da invenção de aparelhos e sistemas tecnocientíficos capazes de aumentar de forma contínua a produção nas mais diversas áreas e com maior economização dos custos do trabalho; por outro, a fabricação de todo o tipo de dispositivos tecnológicos, materiais e imateriais, ou produtos com forte componente tecnológica, sempre de acordo com a expectativa da rentabilidade comercial. Para estes objectivos, o presente artigo realçou o papel da institucionalização da investigação científica e tecnológica como parte da política económica pró-mercantil, a qual tem estado ao serviço de transformações profundas em amplas áreas possíveis de inovação, abrangendo não só produtos e processos, mas também saberes, formas de trabalho, modelos organizacionais e ainda fontes de matérias-primas e estruturas de mercado. Como corolário, têm sido accionadas novas formas de espoliação da natureza e dos seres humanos, desembocando num aumento vertiginoso - e de concentração - de conhecimento e poder, com reverberações perigosas, ora numa escala global, ora em nome do nacionalismo económico. O capitalismo, ao conformar a inovação tecnológica, também é por ela conformado. 
Sob a sedução da ideia falaciosa de que a trajectória da tecnologia e a evolução dos mercados são correlatas ao desenvolvimento directo e linear da racionalidade, perspectiva que aqui se cunhou como manifestação de historicismo tecno-liberal, as mercadorias tecnológicas tanto aparecem enquanto promessa, como justificativas de cada novidade. Assim, o novo tecnológico é concebido de forma necessitarista e teleológica, confirmando sempre as apostas feitas. Em consequência, ficam na obscuridade os interesses, os cálculos económicos, as lógicas de poder, as alternativas possíveis, os conflitos inerentes aos projectos de inovação e às opções tecnológicas. A derrocada de sectores produtivos inteiros e o desemprego tecnológico fazem-se ao compasso da descoberta de novos recursos, da aplicação de métodos de produção, distribuição e consumo, formas de trabalho precárias e fragilizadas ("uberizadas") e da constituição de mercadorias fictícias. São descuradas as consequências inesperadas de todo o tipo, os efeitos catastróficos sociais, os problemas ambientais e a confusão moral que acompanha a inovação. Mesmo na agenda política da promoção da sustentabilidade que aparece a desafiar a orientação dominante da inovação, se bem que os valores ambientais estejam presentes e o foco não seja exclusivamente na produtividade, no lucro e na expansão do mercado, nota-se uma propensão para o solucionismo tecnológico (Morozov, 2014) e para a manutenção de padrões de vida de alto consumo.

A inflação de expectativas relativamente à inovação, mormente em desfavor da implementação de políticas sociais, não tem favorecido uma ampla atitude crítica à orientação dominante da inovação, à inovação como panaceia, à sua inserção no plano meramente tecno-mercantil, ao seu elã cesurial sem parâmetros éticos, sociais e políticos. É necessário avaliar o perfil de valores da inovação para se poder tomar decisões informadas a respeito do que se quer inovar e de como se quer inovar, ter em conta perspectivas alternativas de inovação e atender às resistências à inovação, tudo isto para alcançar fins socialmente equitativos e ecologicamente viáveis.

Revisto por Sofia Silva

\section{Referências bibliográficas}

Alonso Benito, Luis Enrique; Fernández Rodríguez, Carlos J. (2018), Poder y sacrificio. Los nuevos discursos de la empresa. Madrid: Siglo XXI.

Altieri, Miguel A. (2001), Genetic Engineering in Agriculture: The Myths, Environmental Risks, and Alternatives. Oakland: Food First. 
Archibugi, Daniele; Filippetti, Andrea (2011), Innovation and Economic Crisis Lessons and Prospects from the Economic Downturn. London: Routledge.

Arena, Richard; Festré, Agnès; Lazaric, Nathalie (orgs.) (2012), Handbook of Knowledge and Economics. Cheltenham: Edward Elgar Publishing.

Assouly, Olivier (2008), Le capitalisme esthétique: Essai sur l'industrialisation du goût. Paris: Éditions du Cerf.

Audrestsch, David B.; Falck, Oliver; Heblich, Stephan; Lederer, Adam (orgs.) (2011), Handbook of Research on Innovation and Entrepreneurship. Cheltenham: Edward Elgar Publishing.

Barbosa, Marcos (2011), "Formas de autonomia da ciência”, Scientiae Studia, 9(3), 527-561.

Berlin, Isaiah (1954), Historical Inevitability. London: Geoffrey Cumberlege/Oxford University.

Berman, Marshall (1982), All That is Solid Melts into Air: The Experience of Modernity. London/New York: Verso.

Block, Fred (2003), "Karl Polanyi and the Writing of The Great Transformation”, Theory and Society, 32(3), 275-306.

Block, Fred (2012), "Introdução", in Karl Polanyi, A grande transformação - As origens políticas e económicas do nosso tempo. Lisboa: Edições 70, 81-109.

Brynjolfsson, Erik; McAfee, Andrew (2014), The Second Machine Age: Work, Progress, and Prosperity in a Time of Brilliant Technologies. New York: Norton Company.

Caldas, José Castro; Teles, Nuno (2019), "Tecnologia, trabalho e emprego: das controvérsias do passado na economia política aos futuros possíveis", Cadernos do Observatório, n. ${ }^{\circ}$ 11. Consultado a 28.06.2019, em https://www.ces.uc.pt/observatorios/crisalt/ documentos/cadernos/Caderno_11_Tecnologia_Trab_08032019.pdf.

Catroga, Fernando (2009), Os passos do homem como restolho do tempo. Memória e fim do fim da história. Coimbra: Edições Almedina.

Chaminade, Cristina; Lundvall, Bengt-Åke; Haneef, Shagufta (2018), Advanced Introduction to National Innovation Systems. Cheltenham: Edward Elgar Publishing.

Curto, Diogo Ramada; Domingos, Nuno; Jerónimo, Miguel Bandeira (2012), “A grande transformação, de Karl Polanyi: questões de interpretação”, in Karl Polanyi, A grande transformação - As origens políticas e económicas do nosso tempo. Lisboa: Edições 70, 9-37.

Dodgson, Mark; Gann, David; Phillips, Nelson (orgs.) (2013), The Oxford Handbook of Innovation Management. Oxford: Oxford University Press.

Dodgson, Mark; Gann, David; Salter, Ammon (2008), The Management of Technological Innovation: Strategy and Practice. Oxford: Oxford University Press.

Dolata, Ulrich (2014), The Transformative Capacity of New Technologies: A Theory of Sociotechnical Change. London: Routledge. 
Engel, Jerome S. (org.) (2014), Global Clusters of Innovation: Entrepreneurial Engines of Economic Growth around the World. Cheltenham: Edward Elgar Publishing.

Etzkowitz, Henry (2008), The Triple Helix: University-Industry-Government Innovation. New York: Routledge.

Etzkowitz, Henry; Leydesdorff, Loet (1995), “The Triple Helix - University-Industry-Government Relations: A Laboratory for Knowledge-Based Economic Development”, EASST Review, 14(1), 14-19.

Fagerberg, Jan; Martin, Ben R.; Andersen, Esben Sloth (2013), Innovation Studies: Evolution and Future Challenges. Oxford: Oxford University Press.

Fernández-Esquinas, Manuel (2012), "Hacia un programa de investigación en Sociologia de la Innovación”, Arbor, 188(753), 5-18.

Fernández Pérez, Paloma; Rose, Mary B. (orgs.) (2010), Innovation and Entrepreneurial Networks in Europe. New York: Routledge.

Fuchs, Christian; Mosco, Vincent (2015), Marx in the Age of Digital Capitalism. Leiden: Brill Lam Edition.

Fumagalli, Andrea; Lucarelli, Stefano (2007), “A Model of Cognitive Capitalism: A Preliminary Analysis", European Journal of Economic and Social Systems, 20(1), 117-133.

Garcia, José Luís (2006), “Biotecnologia e biocapitalismo global”, Análise Social, XLI(181), 981-1009.

Garcia, José Luís (2012), "El discurso de la innovación en tela de juicio: tecnología, mercado y bien estar humano”, Arbor, 188(753), 19-30.

Garcia, José Luís; Jerónimo, Helena; Carvalho, Tiago (2018), "Methodological Luddism: A Concept for Trying Degrowth to the Assessement and Regulation of Technologies", Journal of Cleaner Production, 197(2), 1647-1653.

Garcia, José Luís; Martins, Hermínio (2008), "O ethos da ciência e as suas transformações contemporâneas, com especial atenção sobre a biotecnologia”, in Manuel Villaverde Cabral; Karin Wall; Sofia Aboim; Filipe Carreira da Silva (orgs.), Itinerários. A investigação nos 25 anos do ICS. Lisboa: Imprensa de Ciências Sociais, 397-417.

Gault, Fred (org.) (2013), Handbook of Innovation Indicators and Measurement. London: Edward Elgar Publishing.

Gellner, Ernest (1992), Reason and Culture. The Historic Role of Rationality and Rationalism. New Jersey: Blackwell Publishers.

Godin, Benoît (2008), "In the Shadow of Schumpeter: William Rupert Maclaurin and the Study of Technological Innovation", Minerva, 46(3), 343-360.

Godin, Benoit (2016), Innovation Contested - The Idea of Innovation over the Centuries. New York: Routledge [orig. 2014].

Godin, Benoit (2017), Models of Innovation. The History of an Idea. Cambridge, MA: MIT Press. 
Godin, Benoît; Vinck, Dominique (orgs.) (2017), Critical Studies of Innovation: Alternative Approaches to the Pro-innovation Bias. Cheltenham: Edward Elgar Publishing.

Granovetter, Marc (1985), "Economic Action and Social Structure: The Problem of Embeddedness”, American Journal of Sociology, 91(3), 481-510.

Grunwald, Armin (2018), "Diverging Pathways to Overcoming the Environmental Crisis: A Critique of Eco-Modernism from a Technology Assessment Perspective”, Journal of Cleaner Production, 197(2), 1854-1862.

Hall, Bronwyn H.; Rosenberg, Nathan (orgs.) (2010), Handbook of the Economics of Innovation, vol. I e II. Amsterdam: Elsevier.

Karlsson, Charlie; Johansson, Borje; Stough, Roger R. (2012), Innovation, Tecnhology and Knowledge. New York: Routledge.

Kerschner, Christian; Wächter, Petra; Nierling, Linda; Ehlers, Melf-Hinrich (2018), "Degrowth and Technology: Towards Feasible, Viable, Appropriate and Convivial Imaginaries", Journal of Cleaner Production, 197, 1619-1636.

Kloppenburg Jr, Jack Ralph (1988), First the Seed: The Political Economy of Pant Biology 1942-2000. Cambridge: Cambridge University Press.

Koselleck, Reinhart (1988), Critique and Crises: Enlightenment and the Pathogenesis of Modern Society. Oxford: Berg Publishers [orig. 1959].

Koselleck, Reinhart (2004), Futures Past: On the Semantics of Historical Time. New York: Columbia University Press [orig. 1979].

Krimsky, Sheldon (2003), Science in the Private Interest. Has the Lure of Profits Corrupted Biomedical Research? Oxford: Rowman \& Littlefield.

Kwok, Allison G.; Grondzik, Walter T. (orgs.) (2011), The Green Studio Handbook: Environmental Strategies for Schematic Design. New York: Architectural Press.

Lacey, Hugh (2005), Values and Objectivity in Science. The Current Controversy about Transgenic Crops. USA: Lexington Books.

Lazzarato, M. (2014), Signs and Machines: Capitalism and the Production of Subjectivity. New York: Semiotext(e).

Lefebvre, Henri (1970), La fin de l'histoire. Paris: Éditions de Minuit.

Lerner, Josh; Stern, Scott (2012), The Rate and Direction of Inventive Activity Revisited. Chicago: University of Chicago Press.

Lundvall, Bengt-Åke; Joseph, K. J.; Chaminade, Cristina; Vang, Jan (2011), Handbook of Innovation Systems and Developing Countries: Building Domestic Capabilities in a Global Setting. Cheltenham: Edward Elgar Publishing.

Martins, Hermínio (2011), Experimentum bumanum. Civilização tecnológica e condição bumana. Lisboa: Relógio D’Água.

Mazzucato, Mariana; Penna, Caetano C. R. (orgs.) (2015), Mission-Oriented Finance for Innovation: New Ideas for Investment-led Growth. London: Rowman \& Littlefield.

Mohr, Jakki; Sengupta, Sanjit; Slater, Stanley (2014), Marketing of High Products and Innovations. Harlow: Pearson [orig. 2001]. 
Morozov, Evgeny (2014), To Save Everything, Click Here: Technology, Solutionism, and the Urge to Fix Problems that Don't Exist. London: Penguin Books.

Moulaert, Frank; MacCallum, Diana; Mehmood, Abid; Hamdouch, Abdelillah (2013), The International Handbook on Social Innovation: Collective Action, Social Learning and Transdisciplinary Research. Cheltenham: Edward Elgar Publishing.

Mould, Oli (2018), Against Creativity. London/New York: Verso.

Moulier-Boutang, Yann (2011), Le capitalisme cognitif, comprendre la nouvelle grande transformation et ses enjeux. Paris: Éditions Amsterdam.

Mumford, Michael D. (org.) (2012), Handbook of Organizational Creativity. London: Academic Press.

Murteira, Mário (2004), Economia do conbecimento. Conbecimento, capital e trabalho no mercado global. Lisboa: Quimera.

Niwa, Tiago Hideki (2016), Universidade, indústria e desenvolvimento: a inovação tecnológica em uma economia baseada no conbecimento. Curitiba: Appris Editora.

Nowotny, Helga; Pestre, Dominique; Schulze-Fielitz, Helmuth; Schmidt-Assmann, Eberhard; Trute, Hans-Heinrich (2010), The Public Nature of Science under Assault. Berlin/Heidelberg/New York: Springer.

Osterwalder, Alexander; Pigneur, Yves (orgs.) (2010), Business Model Generation: A Handbook for Visionaries, Game Changers, and Challengers. Hoboken: John Wiley.

Pasquinelli, Matteo (2015), "Italian Operaismo and the Information Machine", Theory, Culture \& Society, 32(3), 49-68.

Pestre, Dominique (2003), Science, argent et politique. Un essai d'interprétation. Paris: INRA.

Picciano, Anthony G.; Spring, Joel (2012), The Great American Education-Industrial Complex. New York: Routledge.

Polanyi, Karl (2012), A grande transformação - As origens políticas e económicas do nosso tempo. Lisboa: Edições 70. Tradução de Miguel Serras Pereira [orig. 1944].

Pollex, Jan; Lenschow, Andrea (2018), “Surrendering to Growth? The European Union's Goals for Research and Technology in the Horizon 2020 Framework", Journal of Cleaner Production, 197(2), 1863-1871.

Popper, Karl (1957), The Poverty of Historicism. New York: Routledge/Kegan Paul.

Portes, Alejandro (2010), Economic Sociology: A Systematic Inquiry. Princeton: Princeton University Press.

Powell, Walter W.; Snellman, Kaisa (2004), “The Knowledge Economy”, Annual Review of Sociology, 30, 199-220.

Redford, Dana T. (org.) (2013), Handbook de educação em empreendedorismo no contexto português. Porto: Universidade Católica Editora.

Rooney, David; Hearn, Greg; Kastelle, Tim (orgs.) (2012), Handbook on the Knowledge Economy. Cheltenham: Edward Elgar Publishing. 
Rowan, David (2019), Non-Bullshit Innovation. Radical Ideas from the World's Smartest Minds. London: Bantam Press.

Santos, Rui (2012), "Polanyi e a sociologia económica”, in Karl Polanyi, A grande transformação-As origens políticas e económicas do nosso tempo. Lisboa: Edições 70, 39-64.

Schiller, Dan (1999), Digital Capitalism: Networking the Global Market System. Cambridge, MA: MIT Press.

Schilling, Melissa A. (2017), Strategic Management of Technological Innovation. New York: MacGraw-Hill.

Schumpeter, Joseph A. (1976), Capitalism, Socialism and Democracy. Michigan: Allen and Unwin [orig. 1942].

Schumpeter, Joseph A. (1996), Ensaios, empresários, inovação, ciclos de negócio e evolução do capitalismo. Oeiras: Celta. Tradução de Maria Inês Mansinho e Ezequiel de Almeida Pinho.

Shiva, Vandana (1997), Biopiracy: The Plunder of Nature and Knowledge. Boston: South End Press.

Schwab, Kalus (2017), The Fourth Industrial Revolution. New York: Crown Business.

Smits, Ruud E.; Kuhlmann, Stefan; Shapira, Phillip (orgs.) (2010), The Theory and Practice of Innovation Policy: An International Research Handbook. Cheltenham: Edward Elgar Publishing.

Stoneman, Paul (org.) (1995), Handbook of the Economics of Innovation and Technological Change. Oxford: Blackwell.

Stoneman, Paul (2010), Soft Innovation: Economics, Product Aesthetics and the Creative Industries. Oxford: Oxford University Press.

Strand, Roger; Saltelli, Andrea; Giampietro, Mario; Rommetveit, Kjetil; Funtowicz, Sílvio (2018), “New Narratives for Innovation”, Journal of Cleaner Production, 197(2), 1849-1853.

Sveiby, Karl-Erik; Gripenberg, Pernilla; Segercrantz, Beata (2012), Challenging the Innovation Paradigm. New York: Routledge.

Swann, Peter (2009), The Economics of Innovation: An Introduction. Cheltenham: Edward Elgar Publishing.

Swann, Peter (2014), Common Innovation: How We Create the Wealth of Nations. Cheltenham: Edward Elgar Publishing.

Swedberg, Richard (2003), Principles of Economic Sociology. Princeton: Princeton University Press.

Teece, David J. (2012), Strategy, Innovation and the Theory of the Firm. Cheltenham: Edward Elgar Publishing.

Teles, Nuno; Caldas, José Castro (2019), “Tecnologia e trabalho no século XXI: uma proposta de abordagem”, Cadernos do Observatório, n. ' 12. Consultado a 28.06.2019, em https://www.ces.uc.pt/observatorios/crisalt/documentos/cadernos/Caderno_12_ Tecnologia_e_Trabalho_no_seculo_XXI_08032019.pdf. 
Van de Ven, Andrew H.; Polley, Douglas; Garud, Raghu; Venkataraman, Sankaran (2008), The Innovation Journey. Oxford: Oxford University Press.

Vercellone, Carlo (2005), The Hypothesis of Cognitive Capitalism. London: Birkbeck College/SOAS.

Verganti, Roberto (2009), Design-Driven Innovation: Changing the Rules of Competition by Radically Innovating what Things Mean. Boston: Harvard Business Press. von Hippel, Eric (2006), Democratizing Innovation. Cambridge, MA: The MIT Press. von Hippel, Eric (2017), Free Innovation. Cambridge, MA: The MIT Press.

Artigo recebido a 25.01.2019

Aprovado para publicação a 05.04.2019

\section{José Luís Garcia}

Instituto de Ciências Sociais da Universidade de Lisboa Av. Prof. Aníbal Bettencourt n. ${ }^{\circ}$ 9, 1600-189 Lisboa, Portugal

Contacto: jlgarcia@ics.ulisboa.pt

ORCID: https://orcid.org/0000-0002-9387-9047

\section{A Crucial Task for the Political Economy: A Critique of Techno- -liberal Innovation}

The article undertakes a criticism of innovation, which since the late $20^{\text {th }}$ century, is seen as driving the great project of societies. The text presents two main contributions to clarify what is at stake. The first consists of arguing that the inclination toward innovation is an economic policy of a neoliberal nature whose objective is to increase productivity and profits through the annexation of science and technology, thus opening the way for markets to enter new dimensions of the natural world and human life. The second suggests that the project of innovation is a new manifestation of historicism, namely, techno-liberal historicism. The article concludes with a defence of the need to assess the policies of innovation according to those values

\section{Une tâche cruciale pour l'économie politique: la critique de l'innovation techno-libérale}

L'article vise à critiquer l'innovation mise en avant, depuis les dernières décennies du xxe siècle, comme étant le grand projet des sociétés. Le texte apporte deux contributions principales à l'élucidation de ce qui est en jeu. La première consiste à soutenir que l'orientation visant l'innovation est une politique économique, au caractère néolibéral, qui a pour but d'augmenter la productivité et les bénéfices, par le truchement de l'annexion de la science et de la technologie et en ouvrant aux marchés la voie de nouveaux domaines naturels et de la vie humaine. La seconde suggère que le projet de l'innovation est une nouvelle manifestation d'historicisme, à proprement parler d'historicisme techno-libéral. Nous concluons en défendant le besoin d'évaluer 
adequate for achieving socially equitable and ecologically viable ends.

Keywords: economy of knowledge; historicism; innovation policy; neoliberalism; technological innovation. les politiques d'innovation selon des valeurs étant à même d'atteindre des fins socialement équitables et écologiquement viables. Mots-clés: économie du savoir; historicisme; innovation technologique; néolibéralisme; politique d'innovation. 